\title{
Microglial p38 $\alpha$ MAPK is a key regulator of proinflammatory cytokine up-regulation induced by toll-like receptor (TLR) ligands or beta-amyloid $(A \beta)$
}

Adam D Bachstetter ${ }^{1}$, Bin Xing ${ }^{1}$, Lucia de Almeida ${ }^{2}$, Edgardo R Dimayuga ${ }^{1}$, D Martin Watterson ${ }^{3}$ and Linda J Van Eldik ${ }^{1,4^{*}}$

\begin{abstract}
Background: Overproduction of proinflammatory cytokines from activated microglia has been implicated as an important contributor to pathophysiology progression in both acute and chronic neurodegenerative diseases. Therefore, it is critical to elucidate intracellular signaling pathways that are significant contributors to cytokine overproduction in microglia exposed to specific stressors, especially pathways amenable to drug interventions. The serine/threonine protein kinase p38 $\alpha$ MAPK is a key enzyme in the parallel and convergent intracellular signaling pathways involved in stressor-induced production of IL-1 $\beta$ and TNF $\alpha$ in peripheral tissues, and is a drug development target for peripheral inflammatory diseases. However, much less is known about the quantitative importance of microglial p38 $\alpha$ MAPK in stressor-induced cytokine overproduction, or the potential of microglial p38 $\alpha$ MAPK to be a druggable target for CNS disorders. Therefore, we examined the contribution of microglial p38 $\alpha$ MAPK to cytokine up-regulation, with a focus on the potential to suppress the cytokine increase by inhibition of the kinase with pharmacological or genetic approaches.
\end{abstract}

Methods: The microglial cytokine response to TLR ligands $2 / 3 / 4 / 7 / 8 / 9$ or to $A \beta_{1-42}$ was tested in the presence of a CNS-penetrant p38 $\alpha$ MAPK inhibitor, MW01-2-069A-SRM. Primary microglia from mice genetically deficient in p38 $\alpha$ MAPK were used to further establish a linkage between microglia p38 $\alpha$ MAPK and cytokine overproduction. The in vivo significance was determined by p38 $\alpha$ MAPK inhibitor treatment in a LPS-induced model of acute neuroinflammation.

Results: Increased IL-1 $\beta$ and TNF $\alpha$ production by the BV-2 microglial cell line and by primary microglia cultures was inhibited in a concentration-dependent manner by the p38 $\alpha$ MAPK-targeted inhibitor. Cellular target engagement was demonstrated by the accompanying decrease in the phosphorylation state of two p38 $\alpha$ MAPK protein substrates, MK2 and MSK1. Consistent with the pharmacological findings, microglia from p38 $\alpha$-deficient mice showed a diminished cytokine response to LPS. Further, oral administration of the inhibitor blocked the increase of IL-1 $\beta$ in the cerebral cortex of mice stressed by intraperitoneal injection of LPS.

Conclusion: The p38 $\alpha$ MAPK pathway is an important contributor to the increased microglial production of proinflammatory cytokines induced by diverse stressors. The results also indicate the feasibility of targeting p38 $\alpha$ MAPK to modulate CNS proinflammatory cytokine overproduction.

Keywords: Microglia, cytokines, toll-like receptors, knockout mice, p38alpha mitogen-activated protein kinase, amyloid beta-peptides, drug discovery

\footnotetext{
* Correspondence: linda.vaneldik@gmail.com

'Sanders-Brown Center on Aging, University of Kentucky, Lexington, KY, USA

Full list of author information is available at the end of the article
} 


\section{Background}

Microglia, the resident macrophages of the central nervous system (CNS), monitor their environment through a constant movement of their processes, and respond to local stressors and immune disturbances [1,2]. Microglia express a complement of pattern recognition receptors (PRR) that can respond to pattern associated molecular patterns (PAMPs) and damage associated molecular patterns (DAMPs), such as Lipopolysaccharides (LPS) and $\beta$-amyloid (A $\beta)$. A major class of PRRs includes the Toll-like receptors (TLRs) that play a pivotal role in host defense by regulating innate immunity and linking with adaptive immune responses (for reviews, see: $[3,4]$ ). Activation of TLRs on microglia leads to the production of inflammatory mediators, such as IL-1 $\beta$, IL-6, TNF $\alpha$, and nitric oxide. TLR engagement and signaling in the CNS provide an important defense mechanism by which microglia respond to external pathogens or host-derived ligands. Microglia can also be activated by inflammatory mediators (e.g. cytokines and chemokines) from autocrine, paracrine, and endocrine sources (for detailed reviews on microglia, see: [5,6]). The local environment, and possibly intrinsic changes to the microglia determine how the cells will respond to the activating signals $[7,8]$. Like peripheral immune cells, microglia can adopt a number of activated phenotypes, and the functional outcome depends on a complex balance between beneficial protective responses and detrimental harmful responses [9]. Tight regulation of microglial activation pathways is essential for appropriate responses to stressor stimuli and maintenance of CNS homeostasis, because uncontrolled or dysregulated inflammatory responses can lead to propagation of detrimental and neurotoxic responses.

A relevant example is the control of microglia proinflammatory cytokine production in response to various ligands. Proinflammatory cytokines have many important physiological functions in the CNS, from protection against pathogens to acting as neuromodulators affecting cognition [10]. However, clinical studies and preclinical animal models have implicated dysregulation and overproduction of proinflammatory cytokines from activated microglia in the CNS as a contributor to pathophysiology progression in both chronic neurodegenerative disorders such as Alzheimer's disease (AD), Parkinson's disease, and multiple sclerosis, as well as acute neurodegenerative conditions such as traumatic brain injury and stroke [11-13]. Taken in its entirety, the evidence is consistent with the hypothesis that proinflammatory cytokine overproduction is a comparatively early event in the progression of pathophysiology that is causally linked to synaptic dysfunction, behavior deficits and, in the more extreme case, neuronal death. This raises the possibility that up-regulation of proinflammatory cytokine production could be targeted in new therapeutic development strategies with potential for disease modification in multiple diseases and clinical presentations.

One approach to targeting CNS cytokine dysregulation is to modulate the intracellular signal transduction cascades that regulate the production of proinflammatory cytokines. This requires that we explore which specific signal transduction pathways are involved in cytokine overproduction in microglia exposed to different stressors, and which of these pathways are amenable to intervention. A major signaling pathway that contributes quantitatively to up-regulated cytokine production in peripheral inflammation is the p38 mitogen activated protein kinase (MAPK) pathway, especially the key regulatory enzyme p38 $\alpha$ MAPK $[14,15]$. The p38 $\alpha$ MAPK is amenable to therapeutic intervention in peripheral inflammatory diseases, and treatment with $\mathrm{p} 38 \alpha$ MAPK-targeted inhibitors can suppress cytokine levels back towards basal. There is increasing evidence that the p38 MAPK signaling cascade also contributes to CNS cytokine overproduction and neurodegenerative sequelae, and that it may be a good therapeutic target for CNS disorders characterized by increased proinflammatory cytokine production as a contributor to neurologic dysfunction or susceptibility to injury $[11,16]$. However, studies are needed to determine a direct linkage between the p38 $\alpha$ MAPK-mediated pathway in microglia and proinflammatory cytokine production in response to different stressors. In addition, whether the pathway in microglia is druggable; i.e., responsive to intervention with CNS-penetrant kinase inhibitors, needs to be determined.

The field has been limited in its ability to pursue these questions because of the lack of selective p38 $\alpha$ MAPK inhibitors with sufficient brain penetrance and metabolic stability for use in CNS disorders [17]. We recently developed a selective, orally bioavailable, CNS-penetrant, small molecule p38 $\alpha$ inhibitor, MW01-2-069A-SRM (069A) [18]. Compound 069A attenuates hippocampal proinflammatory cytokine overproduction and leads to improved neurologic outcomes in an AD-relevant mouse model when administered orally at a low dose and in a clinically relevant time window of disease progression; specifically, 069A suppressed the $A \beta_{1-42^{-}}$ induced hippocampal IL-1 $\beta$ and TNF $\alpha$ up-regulation back towards basal and attenuated the resultant synaptic dysfunction and behavioral deficits [18]. These data provided an initial causative link between p38 $\alpha$ MAPK and CNS disease-related endpoints. Moreover, pharmacological downregulation of IL- $1 \beta$ production may have important protective consequences, as IL- $1 \beta$ can induce the expression and activation of p38 MAPK in neurons, promoting tau phosphorylation and loss of the synaptic protein synaptophysin $[19,20]$. The availability of this 
p38 $\alpha$ MAPK inhibitor, as well as a novel mouse model where $\mathrm{p} 38 \alpha$ MAPK is genetically deleted in microglia, provide the opportunity to test whether p38 $\alpha$ MAPK is a major regulator of microglial proinflammatory cytokine overproduction in response to specific stressors, and whether this signaling pathway is amenable to intervention. We report here that $\mathrm{p} 38 \alpha$ MAPK is a key contributor to microglia proinflammatory cytokine production in response to a variety of stressor stimuli, including $A \beta_{1-42}$ and different TLR ligands. In addition, inhibition of p38 $\alpha$ MAPK by either pharmacological or genetic approaches leads to a reduction in microglia cytokine production. The results indicate the feasibility of targeting $\mathrm{p} 38 \alpha \mathrm{MAPK}$ in attempts to modulate proinflammatory cytokine overproduction, a potential contributor to CNS disease progression and susceptibility.

\section{Methods \\ Reagents \\ Toll-like receptor (TLR) ligands}

Lipopolysaccharides (LPS) from Salmonella enterica serotype typhimurium (Sigma-Aldrich, St. Louis, MO: Cat. no. L6143-1MG; EU/MG of LPS is 600,000) was prepared in sterile $0.9 \%$ sodium chloride. The following TLR ligands were prepared according to the manufacturer instructions (InvivoGen, San Diego, CA): the TLR2 ligand, lipoteichoic acid (LTA) from Staphylococcus aureus $(10 \mu \mathrm{g} / \mathrm{ml})$, (cat. no. tlrl-pslta); TLR-3 ligand, polyinosine-polycytidylic acid (poly(I:C)) low molecular weight $(1 \mathrm{mg} / \mathrm{ml})(0.2-1 \mathrm{~kb}$; cat. no. tlrl-picw) and a high molecular weight $(50 \mu \mathrm{g} / \mathrm{ml})(1.5-8 \mathrm{~kb}$; cat. no. tlrl-pic); TLR7/8 ligand, CL097, (500ng/ml)(cat. no. tlrl-c97); and TLR 9 ligand, type B CpG oligonucleotide, ODN1668 (500ng/ml)(cat. no. tlrl-modnb).

\section{Oligomeric $A \beta_{1-42}$}

Oligomeric $A \beta_{1-42}$ was prepared from recombinant $A \beta_{1-}$ 42 peptide (rPeptide, Athens, GA: cat. no. A-1002-2) as previously described $[21,22]$. Briefly, the $A \beta$ peptide was monomerized in $1 \mathrm{mM}$ hexafluoroisopropanal (HFIP) (Sigma-Aldrich, St. Louis, MO), and the HFIP was evaporated using a SpeedVac. The dried peptide film was stored in a desiccator at $-20^{\circ} \mathrm{C}$ until use. Oligomeric $\mathrm{A} \beta$ was prepared by resuspending the peptide in $5 \mathrm{mM}$ dimethylsulfoxide (DMSO) (Sigma-Aldrich, St. Louis, MO; cat. no. D2650). The peptide was then diluted to $100 \mu \mathrm{M}$ in phenol red-free F12 media (Promocell, Heidelberg, Germany; cat. no. C-72119). The A $\beta$ solution was incubated for $24 \mathrm{hrs}$ on ice at $4^{\circ} \mathrm{C}$ to allow oligomer formation. Oligomeric $\mathrm{A} \beta$ was used at a final concentration of $5 \mu \mathrm{M}$ for stimulation of rat microglia cultures. Vehicle control used the same volumes of DMSO and F12 media as was used to generate the A $\beta$ peptide preparations and followed all steps as the peptide.

\section{Small molecule p38 $\alpha$ MAPK inhibitor synthesis and compound administration}

The p38 $\alpha$ MAPK inhibitor, 3-phenyl-4-(pyridin-4-yl)-6(4-pyrimidin-2-yl)piperazin-1-yl)pyridazine (MW01-2069A-SRM) (hereafter designated 069A) was synthesized according to the production scheme previously described [18]. Stock solutions of 069A were made in sterile $0.9 \%$ sodium chloride that was free of preservatives (Hospira, Inc., Lake Forest, IL: cat. no. NDC 04094888-10). Solutions for cell treatments were prepared by dilution of the stock solutions into serum-free media immediately before adding to the cells. Compound was added to cell cultures just before addition of the stressor stimulus, except for the experiment in Figure 1C, D that tested different times of compound addition. For in vivo experiments, mice received 069A (5 mg/ $\mathrm{kg}$ ) or the saline

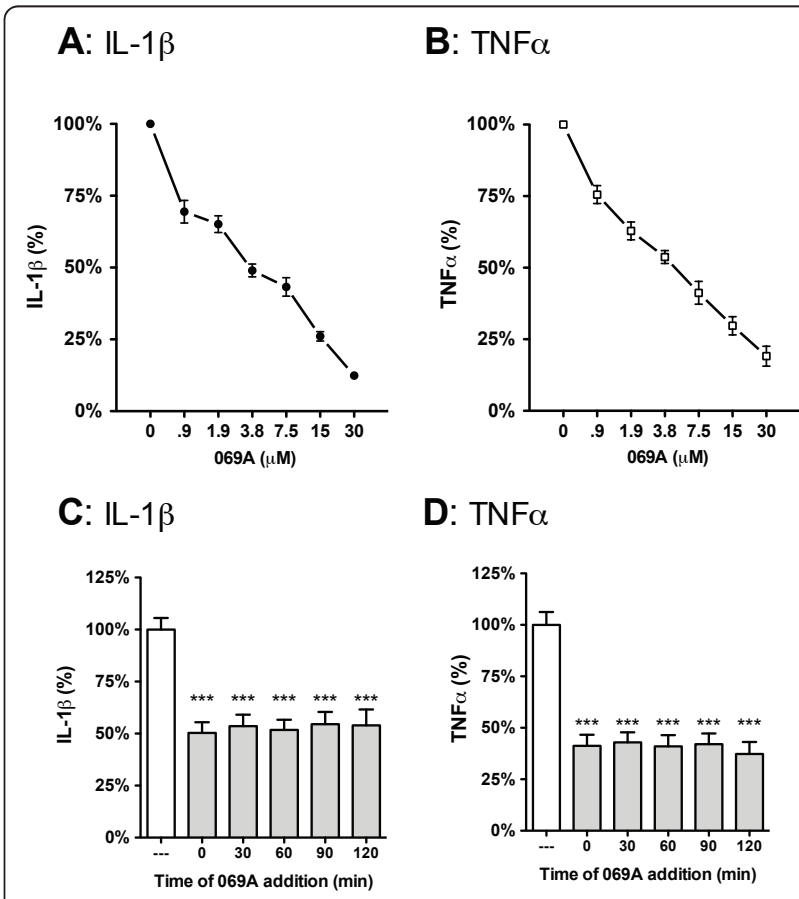

Figure 1 The small molecule p38 $\alpha$ MAPK inhibitor, 069A, suppresses the LPS-induced increase in cytokine production by the BV-2 microglia cell line. BV-2 cells were stimulated with $100 \mathrm{ng} / \mathrm{ml}$ of LPS in the absence or presence of increasing concentrations of 069A (0.9 - $30 \mu \mathrm{M})$. 069A inhibited LPS-induced IL$1 \beta$ (A) and TNF $\alpha$ (B) production in a concentration-dependent manner, with an $\mathrm{IC}_{50}$ of $3.7 \mu \mathrm{M}$ and $4.5 \mu \mathrm{M}$, respectively. Compound 069A ( $4 \mu \mathrm{M}$ ) was equally as effective in blocking the $\mathrm{IL}-1 \beta$ (C) and TNF $\alpha$ (D) cytokine response to LPS when the compound was given at the same time as LPS (time 0) or when given at different times after LPS exposure. White bars show the response of the LPS stimulated cells in the absence of 069A. Gray bars show the response to LPS in the presence of 069A. Data are expressed as a percent of the maximal activity, where activity in the presence of LPS alone is taken as $100 \%$. Asterisk denotes significance ${ }^{* * *}=p<$ 0.001 ) in response to LPS in the absence (white bars) or presence (gray bars) of 069A. 
vehicle by oral gavage (po) in a volume of $200 \mu \mathrm{L}$ one $\mathrm{hr}$ prior to the LPS injection.

\section{Cel Culture}

Mixed glial cultures were prepared from the cerebral cortex of 1-2 day old neonatal C57Bl/6 mice or Sprague-Dawley rats as previously described [23]. The cells were maintained for 2-6 weeks in $\alpha$-minimum essential medium ( $\alpha$-MEM) supplemented with $10 \%$ fetal bovine serum (FBS) (US Characterized FBS; Hyclone; Cat no. SH3007103N), $100 \mathrm{IU} / \mathrm{ml}$ penicillin, $100 \mu \mathrm{g} / \mathrm{ml}$ streptomycin (Mediatech Cat no. 30-002-CI) and 2mM L-Glutamine (Mediatech Cat no. 25-005-CI). Microglia were isolated from the mixed glial cultures by the shake-off procedure [24]. Briefly, the flasks were shaken for $2 \mathrm{hr}$ at $250 \mathrm{rpm}$ on an orbital shaker at $37^{\circ} \mathrm{C}$, the media containing loosely adherent cells were harvested into 48well plates at $1 \times 10^{5}$ or in a 12 -well plate at $3 \times 10^{5}$. After $30 \mathrm{~min}$, nonadherent cells were removed and fresh serum-free medium supplemented with $5 \mathrm{ng} / \mathrm{ml} \mathrm{M-CSF}$ (R\&D systems; Cat no. 416-ML) was added. The cells were then cultured for $24 \mathrm{hrs}$ before treatment.

The murine microglial BV-2 cell line [25] was cultured in DMEM/F12 (Mediatech; Cat no. \#15-090-CV) supplemented with $10 \% \mathrm{FBS}, 100 \mathrm{IU} / \mathrm{ml}$ penicillin, $100 \mu \mathrm{g} / \mathrm{ml}$ streptomycin (Mediatech Cat no. 30-002-CI) and 2mM L-Glutamine (Mediatech Cat no. 25-005-CI). For experiments, serum-containing medium was removed and cells were treated with stimulus or vehicle control in serum-free medium. Cells were harvested after $1 \mathrm{hr}$ of stimulation for Western blot analysis, and after $18 \mathrm{hrs}$ of stimulation for cytokine measurements.

\section{Animals}

All experiments were conducted in accordance with the principles of animal care and experimentation in the Guide For the Care and Use of Laboratory Animals. The Institutional Animal Care and Use Committees of the University of Kentucky and Northwestern University approved the use of animals in this study. Neonatal C57Bl/6 mice or Sprague-Dawley rats were used to make primary glial cultures. Male and female, 2-monthold, C57Bl/6 mice (Harlan) were used for the in vivo LPS experiment. The p38 $\alpha$ conditional knockout mice were generated as previously described [26]. Briefly, the first exon of the p38 $\alpha$ gene was flanked by two loxP sites, the floxed allele was bred to homozygosity, and then crossed with mice that contain Cre driven by the lysozyme promoter. The mice (all p38 $\alpha^{\mathrm{fl} / \mathrm{fl}}$ and backcrossed to $\mathrm{C} 57 \mathrm{Bl} / 6$ ) are maintained and bred as follows: Female mice that are $\mathrm{p} 38^{\mathrm{fl} / \mathrm{fl}}$ wildtype and not carrying the Cre allele are bred with male mice that are Lys-Cre hemizygotes. This generates litters where $\sim 50 \%$ mice are microglia $\mathrm{p} 38 \alpha$ knockout and $\sim 50 \%$ are $\mathrm{p} 38 \alpha^{\mathrm{fl} / \mathrm{fl}}$ littermates (used as wild-type controls). Genotyping was performed by Transnetyx, Inc (Cordova, TN) to confirm mouse genotypes.

\section{Western blotting}

BV-2 cells or primary microglia were plated in 12 well plates at a density of $1 \times 10^{5}$ cells/well or $3 \times 10^{5}$ cells/ well, respectively. Western blotting analysis was performed as previously described [27]. Cell lysates were prepared in sodium dodecyl sulfate (SDS)-containing sample buffer and equal volumes of cell lysates were separated by $10 \%$ SDS-polyacrylamide gel electrophoresis (SDS-PAGE). After transfer to Immobilon-P membranes (Millipore) and blocking, blots were probed with the following primary antibodies from Cell Signaling Technology (Beverly, MA): rabbit anti-pMSK1 (cat. no. 9595 (1:1000)); rabbit anti-pMK2 (cat. no. 3041 (1:1000)); rabbit anti-pCREB (cat. no. 9191 (1:1000)); and rabbit anti-pATF2 (cat no. 9221 (1:1000)): mouse anti-pp38 $\alpha / \beta$ (cat no. 9216 (1:1000)); rabbit anti-p38 $\alpha / \beta$ (cat no. 9212 (1:1000)); rabbit anti-p38a (cat no. 9218 (1:1000)); mouse anti- $\beta$-Actin (Cat no. 3700 (1:10000)).

\section{In vitro cytokine measurements}

After testing a number of different cell densities, a BV-2 cell density of $2 \times 10^{4}$ in a 48 well plate incubated for 24 hrs prior to addition of stimulus produced the most consistent cytokine response with the lowest intra- and interassay variability (data not shown). Primary microglia were used in 48-well plates at $1 \times 10^{5}$ cells. Levels of TNF $\alpha$ were measured in the conditioned media by ELISA using kits from Meso Scale Discovery (MSD; Gaithersburg, Maryland)(Figure 1\&2) or R\&D Systems (Minneapolis, $\mathrm{MN}$ ) (Figure 3\&4). For IL-1 $\beta$, cell lysates were prepared in lysis buffer containing $20 \mathrm{mM}$ Tris, pH8; $2 \mathrm{mM}$ EDTA; $0.5 \%$ Triton X-100. Levels of IL- $1 \beta$ were measured in the conditioned media by ELISA using kits from MSD (Figure $1 \& 2$ ) or R\&D Systems (Figure 3\&4).

\section{Tissue collection and cytokine measurements}

At 90 min and 6 hrs after LPS administration, mice were injected with an overdose of sodium pentobarbital (Pentasol powder; Vibrac Animal Health, Ft Worth, TX: cat. no. NDC-051311-103-25). Blood was collected for serum cytokine measurements. The mice were then decapitated. The brain was dissected on ice and snapfrozen in liquid nitrogen. The tissue was stored at $-80^{\circ} \mathrm{C}$ until time of use. Brain cortex was homogenized using high shear homogenizer (Omni TH115), in a 1:10 (w/v) of ice-cold freshly prepared lysis buffer consisting of PBS containing $1 \mu \mathrm{g} / \mathrm{ml}$ Leupeptin, $1 \mathrm{mM}$ PMSF, and $1 \mathrm{mM}$ EDTA. The cortical homogenate was centrifuged at $14,000 x g$ for 20 minutes at $4^{\circ} \mathrm{C}$ in a microcentrifuge. Fifty microliters of the resulting supernatant was loaded 


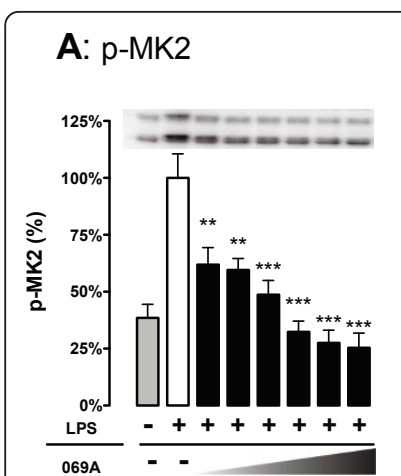

B: p-MSK1

C: $p-C R E B$
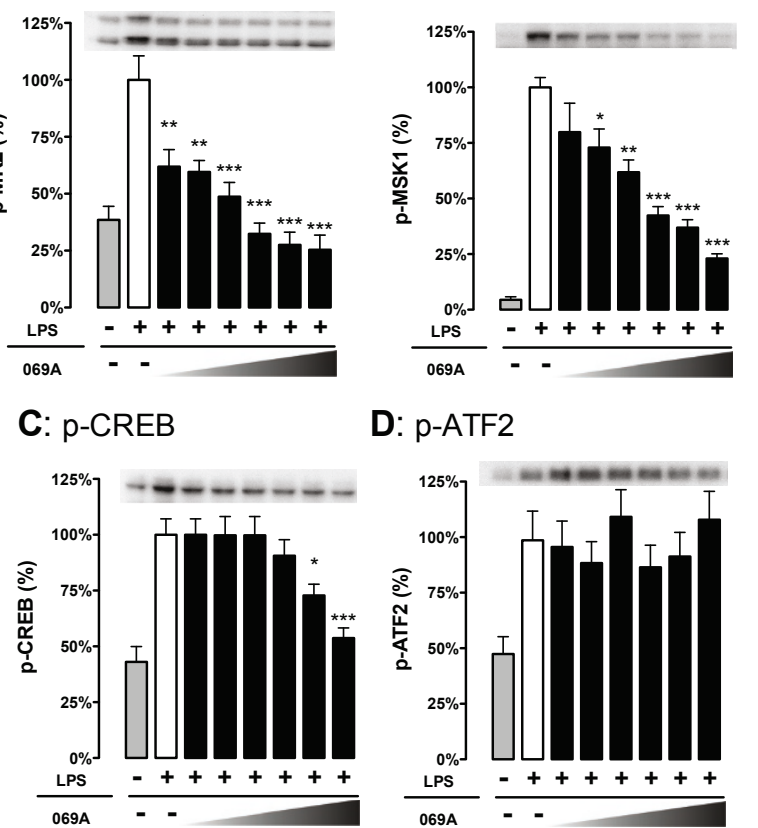

D: $p$-ATF2

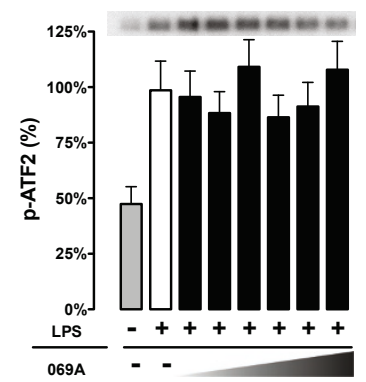

Figure 2 The $p 38 \alpha$ inhibitor, 069A, selectively inhibits phosphorylation of the $\mathrm{p} 38 \alpha$ substrates MK2 and MSK1 in LPSstimulated BV-2 microglia cells. BV-2 cells were stimulated with $100 \mathrm{ng} / \mathrm{ml}$ of LPS in the absence or presence of increasing concentrations of 069A (0.9 - $30 \mu \mathrm{M})$. Levels of (A) p-MK2 and (B) pMSK1 were suppressed by the $\mathrm{p} 38 \alpha$ inhibitor in a concentrationdependent manner. Treatment of cells with 069A had an effect on p-CREB (C) only at the two highest compound concentrations, and had no effect on p-ATF2 levels (D). Gray bars show the response of control, unstimulated cells; white bars show the response of LPSstimulated cells in the absence of 069A; black bars show the response of LPS-stimulated cells in the presence of 069A. For each endpoint, data are expressed as a percent of the maximal activity, where activity in the presence of LPS alone is taken as $100 \%$. Asterisk denotes significance $\left(^{*}=p<0.05,{ }^{* *}=p<0.01\right.$, or ${ }^{* * *}=p$ $<0.001$ ) in endpoint for LPS-stimulated cells (white bars) to LPSstimulated cells in presence of 069A (black bars). Data represent five independent experiments.

per well of the MSD plate, and IL-1 $\beta$ and TNF $\alpha$ levels determined by MSD assay. Cytokine levels in the cortex were normalized to the total amount of protein in the sample loaded as determined by BCA Protein Assay (Pierce). For serum cytokine measurements, $25 \mu \mathrm{l}$ of undiluted serum was loaded per well of the MSD plate, and data expressed as $\mathrm{pg} / \mathrm{ml}$. The detection limits of the MSD assays are $3.4 \mathrm{pg} / \mathrm{ml}$ for TNF $\alpha$ and $1.5 \mathrm{pg} / \mathrm{ml}$ for IL-1 $\beta$ in serum/plasma.

\section{Statistics}

Statistical analysis was conducted using GraphPad prism software version 5 (GraphPad Software, San Diego

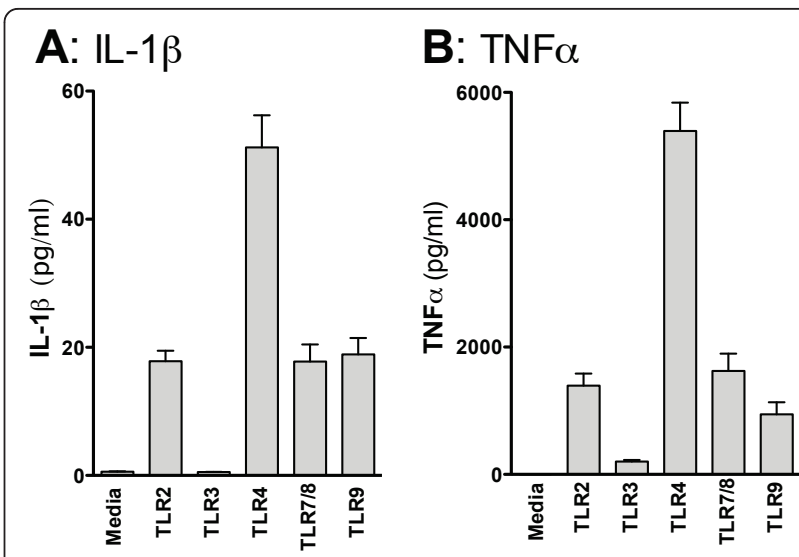

C: IL-1 $1 \beta$

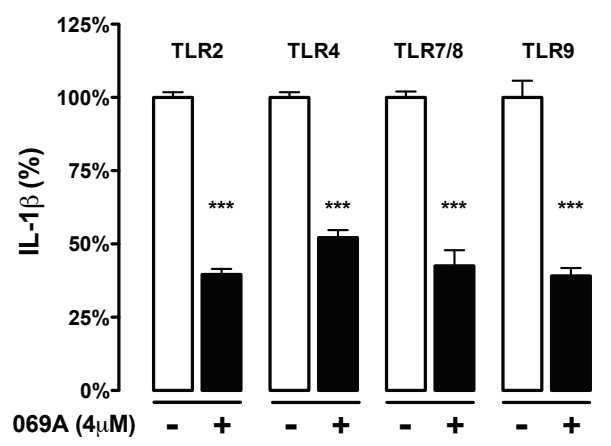

D: $T N F \alpha$

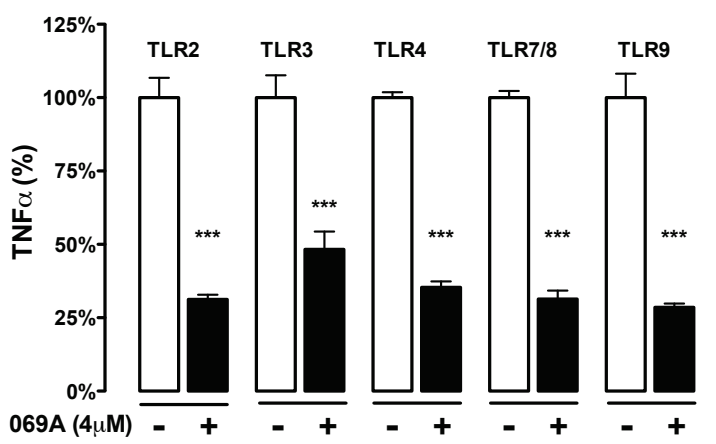

Figure 3 The $p 38 \alpha$ MAPK inhibitor 069A attenuates the IL-1 $\beta$ and TNF $\alpha$ increase in response to diverse TLR ligands. The IL$1 \beta$ (A) and TNF $\alpha$ (B) response from BV-2 cells was measured after $18 \mathrm{hrs}$ of stimulation with either: (TLR2) $10 \mu \mathrm{g} / \mathrm{ml} \mathrm{LTA}$; (TLR3) $50 \mu \mathrm{g} /$ $\mathrm{ml}$ poly(l:C); (TLR4) 100ng/ml LPS; (TLR7/8) 500ng/ml CL097; or (TLR9) $500 \mathrm{ng} / \mathrm{ml}$ ODN1668. Treatment of cells with $4 \mu \mathrm{M}$ of the p38 $\alpha$ inhibitor, 069A, led to a significant reduction in the levels of $I L-1 \beta$ (C) and TNF $\alpha$ (D) in response to each of the different TLR ligands. The white bar represents the BV-2 cells stimulated with the ligand but without 069A (normalized to 100\%). The black bar represents the BV-2 cells treated with TLR ligand $+069 \mathrm{~A}$. Asterisk denotes significance $\left(^{*}=p<0.05,{ }^{* *}=p<0.01\right.$, or ${ }^{* *}=p<$ 0.001) for ligand-stimulated without 069A (white bar) compared to stimulated with 069A (black bar). Data represent two independent experiments. 

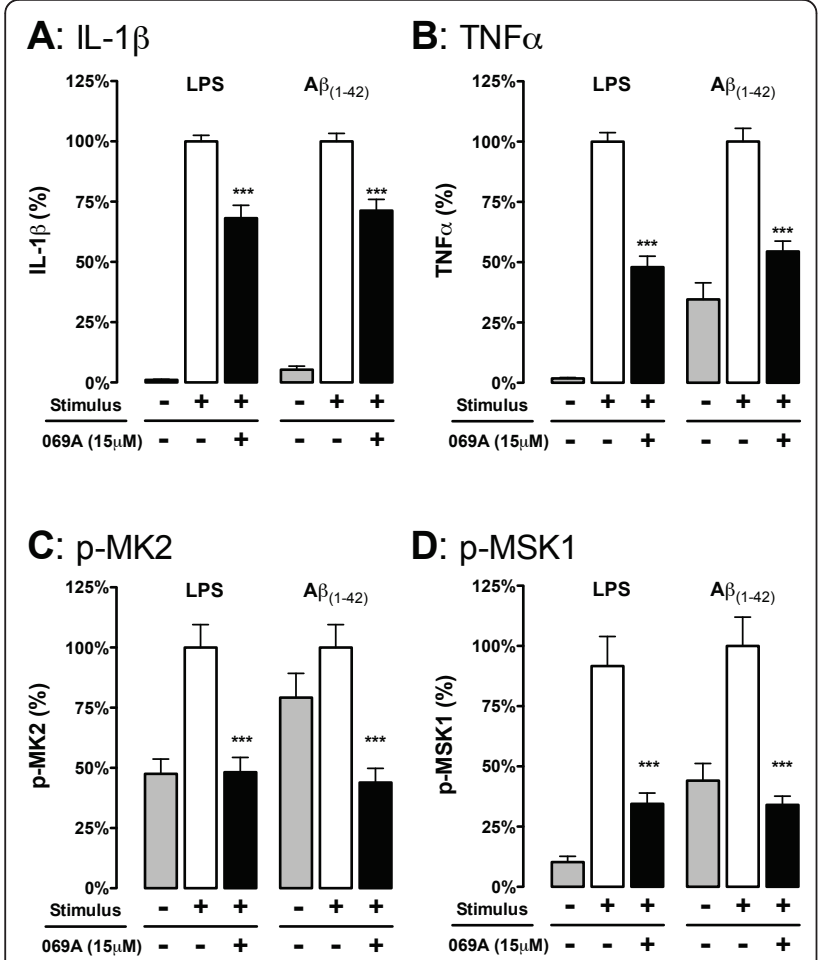

Figure 4 The $p 38 \alpha$ MAPK pathway is engaged in primary microglia and contributes to cytokine upregulation. Rat primary microglia were treated with either diluent (gray bars), stressor (either $1 \mathrm{ng} / \mathrm{ml}$ LPS or $5 \mu \mathrm{M}$ oligomeric $A \beta_{1-42}$ ) in the absence of $069 \mathrm{~A}$ (white bars), or stressor in the presence of $15 \mu \mathrm{M}$ 069A (black bars). The LPS-induced increases in IL-1 $\beta$ (A) and TNF $\alpha$ (B) levels by rat primary microglia were significantly inhibited by the $p 38 \alpha$ inhibitor 069A. Similar results were obtained with a non-TLR ligand, $A \beta_{1-42}$ LPS or A $\beta$ also caused an increase in the phosphorylated (active) form of two p38 $\alpha$ substrates, p-MK2 (C) and p-MSK1 (D), and phosphorylation of these substrates was blocked by the addition of 069A. Asterisk denotes significance $\left(^{*}=p<0.05,{ }^{* *}=p<0.01\right.$, or $\left.{ }^{* * *}=p<0.001\right)$ for stressor-stimulated microglia in the absence of 069A compared to stimulated microglia in the presence of 069A. Values with stimulus alone (white bars) were normalized to $100 \%$. Data represent four independent experiments.

California USA, http://www.graphpad.com). Calculations of $\mathrm{IC}_{50}$ values were made using a nonlinear regression with a variable Hill slope, with the data normalized to the positive control to fit the top and bottom plateaus. Unless otherwise indicated, values are expressed as mean \pm SEM. Groups of 2 were compared by unpaired T-test. Groups of 3 or more were compared by One-way analysis of variance (ANOVA), followed by Bonferroni Multiple Comparison Test. Significance was defined as a p $<0.05$.

\section{Results}

The p38 $\alpha$ MAPK inhibitor, 069A, suppresses LPS-induced cytokine up-regulation in the BV-2 microglial cell line The ability of the small molecule p $38 \alpha$ MAPK inhibitor, compound 069A, to inhibit proinflammatory cytokine up-regulation was tested in the mouse microglial BV-2 cell line. BV-2 cells were treated for $18 \mathrm{hrs}$ with a standard activating stimulus, LPS (100 $\mathrm{ng} / \mathrm{ml})$, in the absence or presence of increasing concentrations of 069A $(0.9 \mu \mathrm{M}$ to $30 \mu \mathrm{M})$, and then levels of IL-1 $\beta$ and TNF $\alpha$ were measured. The results of four independent experiments are shown in Figure 1A, B. Compound 069A produced a concentration-dependent inhibition of both IL-1 $\beta$ (Figure 1A) and TNF $\alpha$ (Figure 1B) levels in LPS-treated cells, reaching greater than $80 \%$ inhibition at the $30 \mu \mathrm{M}$ concentration. The calculated $\mathrm{IC}_{50}$ for suppression of IL-1 $\beta$ was $3.7 \mu \mathrm{M}$, with a $95 \%$ confidence interval of 3.1 to $4.4 \mu \mathrm{M}$. The calculated IC50 for suppression of TNF $\alpha$ was $4.5 \mu \mathrm{M}$, with a $95 \%$ confidence interval of 3.8 to $5.3 \mu \mathrm{M}$.

To provide insight into the temporal action of 069A, we asked whether the compound would be effective when given after stimulation or whether 069A needs to be added to cells before or at the same time as stimulus. We stimulated BV-2 cells with LPS (100 ng/ml), then added 069A (at the $\mathrm{IC}_{50}$ concentration of $4 \mu \mathrm{M}$ ) at 30 min intervals up to 2 hrs after LPS treatment. IL-1 $\beta$ and TNF $\alpha$ levels were then measured at $18 \mathrm{hrs}$ after LPS addition. As expected, $4 \mu \mathrm{M}$ of 069A given at the same time as LPS (time 0) resulted in approximately $50 \%$ inhibition of IL-1 $\beta$ (Figure 1C) and TNF $\alpha$ (Figure 1D). Interestingly, there was no loss in effectiveness when 069A was given even 2 hrs after the LPS stimulation. This was confirmed in two independent experiments.

\section{LPS-induced phosphorylation of p38 substrates, MK2 and MSK1, is reduced selectively by treatment with 069A}

To confirm that 069A was inhibiting the p38 $\alpha$ MAPK pathway and to examine the selectivity of the downstream signaling responses, BV-2 cells were analyzed by western blot for the levels of activated (phosphorylated) p38 target proteins. Figure 2 shows results of five independent experiments. As expected, cells treated with $100 \mathrm{ng} / \mathrm{ml}$ LPS for one hr showed a significant increase $(p<0.05)$ in the levels of the phosphorylated (activated) forms of the four p38 substrates we examined: mitogenactivated protein kinase-activated protein kinase 2 (MK2), mitogen- and stress-activated kinase 1 (MSK1), cyclic AMP response element binding protein (CREB), and activating transcription factor-2 (ATF-2). We explored the ability of 069A to suppress the LPSinduced phosphorylation of the p38 substrates. As shown in Figure 2A, there was strong concentrationdependent inhibition $\left(\mathrm{IC}_{50}\right.$ of $\left.2.8 \mu \mathrm{M}\right)$ of phosphorylated (p)-MK2, a kinase whose activity is dependent on activation by $\mathrm{p} 38 \alpha$ [28]. MSK1 is a kinase that can be phosphorylated by both p38 and Erk1/2 [29]. At a concentration of $1.9 \mu \mathrm{M}$ and higher, 069A significantly 
reduced the amount of p-MSK1, with an $\mathrm{IC}_{50}$ of $6.1 \mu \mathrm{M}$ (Figure 2B). CREB, which is a downstream target of MSK1, was also significantly inhibited by 069A, but only at a compound concentration of $15 \mu \mathrm{M}$ or higher (Figure $2 \mathrm{C}$ ). ATF2 is a target of JNK [30] as well as p38 $\alpha / \beta$ $[31,32]$, and 069A did not inhibit p-ATF2 levels (Figure 2D). These data demonstrate that 069A shows selectivity in its engagement of downstream substrates in the p38 MAPK pathway.

\section{p38 $\alpha$ MAPK is important for the cytokine response to different TLR ligands}

To confirm that the effects of 069A were not limited to LPS stimulation, we tested the ability of 069A to suppress production of cytokines in BV-2 cells treated with a panel of TLR ligands. We chose to examine ligands for TLR2, TLR3, TLR4, TLR7/8, and TLR9 based on three criteria. First, the expression of these receptors has been shown to be elevated in areas of the brain associated with CNS neurodegenerative disease pathology [33]. Second, microglia have been shown to express these receptors [34]. Finally, ligands for these TLRs induced a reproducible cytokine response in BV-2 cells. As shown in Figure 3A, the TLR ligand panel produced a significant increase in IL- $1 \beta$, with the exception of the TLR3 ligand poly(I:C). High molecular weight and low molecular weight versions of poly $(\mathrm{I}: \mathrm{C})$ were tested, but neither version resulted in a significant increase in IL$1 \beta$. All the TLR ligands tested, including the TLR3 ligand poly $(\mathrm{I}: \mathrm{C})$, produced a large and significant $(\mathrm{p}<$ $0.0001)$ TNF $\alpha$ cytokine response (Figure 3B). Both versions of poly(I:C) produced similar increases in TNFa; only data from the high molecular weight version of poly(I:C) is shown.

We tested whether 069A would be effective at blocking the increase in cytokines induced by TLR ligands. As shown in Figure 3C, $4 \mu \mathrm{M}$ 069A significantly $(\mathrm{p}<0.001)$ decreased the amount of IL- $1 \beta$ that was produced by the $\mathrm{BV}-2$ cells in response to each TLR ligand tested. The percent inhibition by 069A with TLR2, TLR7/8, and TLR9 ligands was not significantly different from the inhibition seen with LPS, the TLR4 ligand. Similar results were seen with TNF $\alpha$ production, where 069A treatment resulted in a significant inhibition $(\mathrm{p}<0.001)$ of TNF $\alpha$ levels in response to all the TLR ligands (Figure 3D).

The $\mathrm{p} 38 \alpha$ MAPK pathway is engaged in primary microglia and contributes to cytokine up-regulation

To examine the generality of the response of stressorstimulated microglia to the p38 $\alpha$ inhibitor 069A and confirm that the results were not specific to the BV-2 cell line, we tested primary microglia stimulated with either a TLR ligand (LPS) or a non-TLR ligand $\left(A \beta_{1-42}\right)$. The LPS-induced increases in IL-1 $\beta$ (Figure 4A) and
TNFa (Figure 4B) levels in rat primary microglia were significantly $(\mathrm{p}<0.001)$ inhibited by 069A $(15 \mu \mathrm{M})$. Similar results were obtained with $A \beta_{1-42}$ (Figure 4A, B), demonstrating that the $\mathrm{p} 38 \alpha$ pathway is not limited to TLR ligand activations. We also found that phosphorylation of the p38 $\alpha$ MAPK substrates MK2 (Figure 4C) and MSK1 (Figure 4D) was increased with ligand activation of primary microglia, and that 069A treatment significantly decreased the levels of p-MK2 and p-MSK1.

To complement the pharmacological experiments and confirm the importance of $\mathrm{p} 38 \alpha$, primary microglia were isolated from $\mathrm{p} 38 \alpha$ conditional knockout mice, where p38 $\alpha$ is genetically deficient in macrophages/ microglia. Control cells were microglia isolated from the wild-type littermates. Upon stimulation of the microglia cultures with $1 \mathrm{ng} / \mathrm{ml}$ of LPS, we found an approximately $50 \%$ reduction in the levels of IL- $1 \beta$ (Figure $5 \mathrm{~A}$ ) and TNF $\alpha$ (Figure $5 \mathrm{~B}$ ) in the p38 $\alpha$-deficient microglia compared to the wild-type microglia. Using a p38 $\alpha$-selective antibody, we confirmed by Western blots that essentially no p38 $\alpha$ was detected in the knockout microglia (Figure $5 \mathrm{C}$ ). There also was no compensatory increase in $\mathrm{p} 38 \beta$ in these microglia, as antibodies that react with both p38 $\alpha$ and p38 $\beta$ showed little or no detectable reactivity with the knockout microglia (Figure 5C). Finally, there were substantially reduced levels of $\mathrm{p}-\mathrm{MSK} 1$ or $\mathrm{p}-\mathrm{MK} 2$ in the LPS-treated knockout microglia, confirming that there is little to no activation of the $\mathrm{p} 38 \alpha$ pathway in these microglia. Altogether, these pharmacological and genetic data demonstrate that the p38 $\alpha$ MAPK pathway is activated in ligand-stimulated primary microglia, and that this pathway contributes to the microglial cytokine up-regulation in response to diverse stressors.

\section{Oral administration of 069A suppresses cytokine up- regulation in vivo in response to LPS}

LPS was used to produce an acute inflammatory response in the brain to determine if 069A given orally could reduce the CNS inflammatory response. In our mouse model, we have found that an intraperitoneal (ip) injection of LPS induces IL-1 $\beta$ up-regulation that peaks at 6 hrs after the LPS stimulation (data not shown). Therefore, 069A (5 mg/kg) was administered by oral gavage $1 \mathrm{hr}$ before LPS stimulation, mouse brain was harvested at $6 \mathrm{hrs}$ after LPS addition, and IL-1 $\beta$ levels in the cortex were measured. As shown in Figure 6A, 069A treatment caused a significant $(\mathrm{p}<0.05)$ reduction in the amount of IL-1 $\beta$ produced in the cortex following LPS stimulation compared to the LPS-stimulated mice that received vehicle. IL-1 $\beta$ was not detectable in the non-LPS treated mice (data not shown). TNF $\alpha$ levels in the LPS-treated mice were near basal levels at this time point, so the ability of $069 \mathrm{~A}$ to inhibit TNF $\alpha$ in cortex could not be determined. 

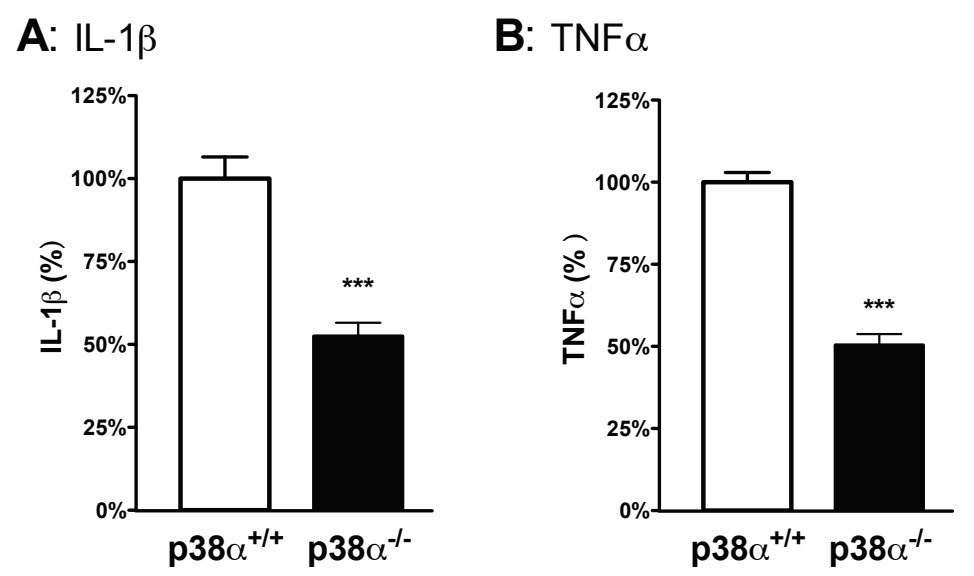

C:

Figure 5 Microglia deficient in p38 $\alpha$ MAPK show a reduced cytokine response to LPS. Primary microglia isolated from either p38 $\alpha$

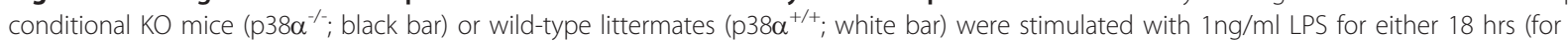
cytokine measurements) or $1 \mathrm{hr}$ (for western blots). There was a significant reduction in the IL-1 $\beta$ (A) and TNF $\alpha$ (B) response to LPS in microglia from the p38 $\alpha \mathrm{KO}$ mice compared to wild-type microglia. (C) There was also substantially reduced LPS-induced phosphorylation of p38 $\alpha$ substrates MSK1 and MK2 in p38 $\alpha^{\%}$ microglia compared to $p 38 \alpha^{+/+}$microglia. The loss of p38 $\alpha$ in the KO microglia was confirmed by little or no reactivity with a phospho-p38 $\alpha / \beta$ antibody, a $p 38 \alpha / \beta$ antibody and a $p 38 \alpha$-selective antibody. Asterisk denotes significance $(* * *=p<0.001)$ for $p 38 \alpha^{+/+}$microglia (white bar) compared to $p 38 \alpha^{-/-}$microglia (black bar). Responses of the wild-type microglia were normalized to $100 \%$. Data represent three independent experiments.

In this acute LPS model, the effect of 069A could be to inhibit the production of IL- $1 \beta$ from microglia, as demonstrated in the cell culture studies. However, 069A could also be lessening the initial response in the periphery to LPS and thereby reducing the severity of the response in the CNS. To begin to address this possibility, we tested the potential of 069A to block the serum cytokine response to LPS using a 90 min time point that we have previously found to be the time of peak response of serum TNF $\alpha$ to an ip LPS challenge. As shown in Figure 6B, 069A did significantly reduce the serum TNF $\alpha$ levels in mice administered LPS for 90 min $(\mathrm{p}<0.05)$. The serum IL-1 $\beta$ levels were low and there was no inhibition by 069A at this time point.

\section{Discussion}

We report here several findings with important implications for the treatment of CNS inflammation. First, we show using both pharmacological and genetic approaches that the p38 $\alpha$ MAPK isoform is sufficient for blocking a substantial portion of the IL-1 $\beta$ and TNF $\alpha$ produced by microglia following LPS stimulation. Second, using primary microglia and a microglia cell line we show that the brain-penetrant $\mathrm{p} 38 \alpha$ inhibitor, 069 $\mathrm{A}$, is able to block the cytokine response to diverse, disease-relevant stimuli. Third, we demonstrate in vivo that a single oral dose of 069A can block the IL-1 $\beta$ response in the brain to a peripheral LPS insult. Fourth, we show that 069A inhibits the activation of known downstream targets of $\mathrm{p} 38 \alpha$, namely MK2 and MSK1, and demonstrates selectivity in the signal transduction pathways that it affects. Altogether, our data support the idea that the p38 $\alpha$ MAPK pathway is quantitatively important for microglia proinflammatory cytokine upregulation in response to a variety of stressors, and that the kinase may be a viable drug discovery target for CNS disorders where overproduction of proinflammatory cytokines has been implicated in disease progression.

Cytokines are inflammatory mediators that act throughout the body, including the CNS, via specific receptors and signal transduction pathways. Clinical studies and preclinical animal models have provided extensive evidence to support the hypothesis that overproduction of proinflammatory cytokines contributes to the progression of chronic neurodegenerative disorders (for review, see [11]), as well as to increased susceptibility to later-in-life disease or secondary injuries [35]. Microglia are the primary cell type in the CNS responsible for the production of cytokines. We were able to inhibit the production of two key proinflammatory cytokines, IL-1 $1 \beta$ and TNF $\alpha$, with the p38 $\alpha$ MAPK inhibitor 069A at concentrations consistent with its ability to block p38 $\alpha$ kinase activity. Interestingly, we found that 069A was equally effective at blocking the production of cytokines when the compound was given up to two hrs after the LPS treatment; however, the mechanism underlying this observation was not pursued as part of this study. The observation that 069A also suppresses the phosphorylation of two direct p38 substrates, MK2 and MSK1, provides additional evidence of target engagement in the microglial cells. The inhibition of the active phosphorylated form of MK2 upon 069A treatment is consistent 


\section{A: cortex cytokine levels}
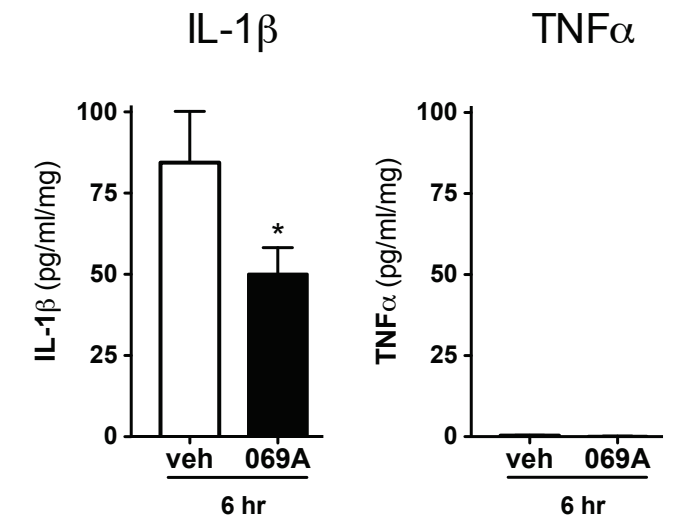

\section{B: serum cytokine levels}
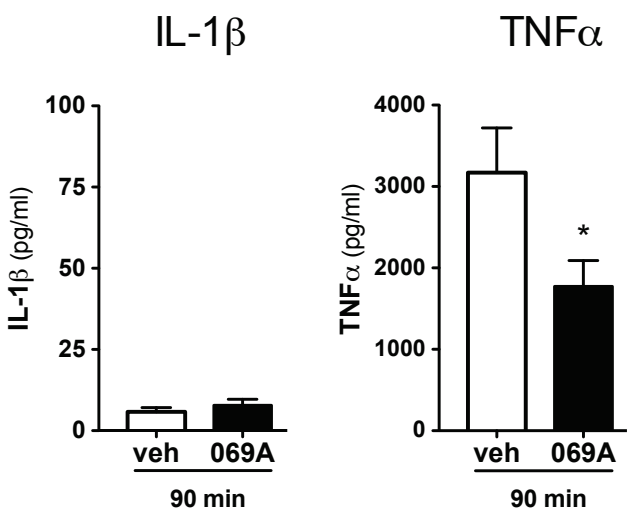

Figure 6 Oral administration of 069A suppresses LPS-induced cortical IL-1 $\beta$ and serum TNF $\alpha$ in vivo: $\mathrm{C} 57 \mathrm{BI} / 6$ mice were administered either saline vehicle or 069A $(5 \mathrm{mg} / \mathrm{kg})$ by oral gavage one hr prior to an intraperitoneal LPS $(1 \mathrm{mg} / \mathrm{kg})$ injection. Serum and cortex were harvested at $90 \mathrm{~min}$ and $6 \mathrm{hrs}$, respectively, after LPS injection. (A) At the $6 \mathrm{hr}$ timepoint, IL-1 $\beta$ levels were significantly lower in the cortex of mice treated with 069A compared to vehicle-treated mice. TNF $\alpha$ levels in the cortex were at or near the limit of detection of the assay. (B) At the 90 min timepoint, TNF $\alpha$ levels were significantly lower in the serum of mice treated with 069A compared to vehicle-treated mice. Serum IL-1 $\beta$ levels were low, and there was no inhibition by 069A at this timepoint. Asterisk denotes significance $\left({ }^{*}=p<0.05\right)$ for vehicletreated mice (white bar) compared to 069A-treated mice (black bar). $\mathrm{N}=5-8$ per group.

with the observation [36] that MK2 kinase activity is dependent on $\mathrm{p} 38 \alpha$ MAPK for its phosphorylation and activation. MK2 has also been reported to directly regulate TNF $\alpha$ at the 3'-untranslated region (UTR) of mRNA in the AU-rich elements [37], suggesting a potential mechanistic explanation for the action of 069A in suppression of cytokine production. MSK1 can be phosphorylated and activated by both p38 $\alpha$ MAPK and ERK1/2 [29]. However, our observation that inhibition of $\mathrm{p} 38 \alpha$ MAPK by 069A or by genetic deletion leads to suppression of phosphorylated MSK1 in the microglia cultures suggests that the p38 $\alpha$ MAPK pathway is playing a key role in transducing the stressor stimulus to cytokine production in microglia.

In AD-relevant models, TLR2 and TLR4 have been shown to be required for microglia cytokine response to fibrillar A $\beta$ [38]. Microglia associated with senile plaques exhibit elevated levels of TLR2/4/5/7/9 [33]. While the role of TLRs in AD may be the best defined for any CNS disorder to date, the potentially neurotoxic role of TLRs is not limited to AD (for a recent review see: $[39,40])$. The inflammatory cytokine response to TLR ligands is typically through NF- $\kappa \mathrm{B}$ and MAPK signal transduction pathways [41]. However, the response to the ligands can vary depending on the cell type activated. In BV-2 cells we found that 069A was highly effective at blocking the inflammatory cytokine response to TLR $2 / 3 / 4 / 7 / 8 / 9$ ligands. This suggests that $\mathrm{p} 38 \alpha$ plays an important role in the signal transduction pathways that lead to inflammatory cytokines in microglia in response to a variety of ligands, and that this kinase may prove to be an effective convergence point that can be targeted by small molecule inhibitors, such as 069A, to block cytokine overproduction. Blocking p38 $\alpha$ MAPK in microglia, a principle source of inflammatory cytokines such as IL-1 $\beta$, may ameliorate the detrimental sequelae of increases in neuronal tau phosphorylation, synaptic loss, or other cytokine-induced neuronal damage responses [42-45]. In addition, inhibition of p38 MAPK in the neuron may also have beneficial consequences. Particularly relevant to AD, for example, are reports showing that activation of neuronal p38 MAPK contributes to A $\beta$-induced impairment of cortical LTP [46], and that p38 MAPK can phosphorylate tau in vitro at sites seen in AD brain $[47,48]$.

It should be emphasized that microglia responses to stimuli can be neuroprotective and assist with phagocytosis or protein aggregate clearance, or can be detrimental and contribute to a progression of pathology [13,49-51]. Therefore, attempts to develop disease-modifying therapeutics that target microglial activation responses must be selective in their action (e.g., NOT be pan-suppressors of glial activation such as steroids), must consider the stage of disease progression and the relative contribution of a given endpoint or signaling pathway to the particular disease stage, and the appropriate dosing.

Dosing is the pharmacological foundation to selective therapeutic intervention. Dosing includes the amount of drug given normalized to body weight or volume and includes the therapeutic time window for administration. The desired effect of a drug, therefore, requires a combination of timing of administration based on 
mechanism of action and the amount administered. It is a given that all drugs will have an adverse effect at some dose, so safety with efficacy depends on finding the appropriate concentration range over which the desired effects are observed in the absence of undesired effects. However, one can also obtain pharmacological selectivity with dosing, or one pharmacological effect at one dose range and additional desired effects across a higher dose range. Examples from prior art relative to modulating inflammation are instructive in this regard. Steroids are used as anti-inflammatories, but are pleiotropic in their actions. The pleiotropic effect contributes to a diversity of pharmacological actions across efficacious doses and to a comparatively narrow therapeutic range in the absence of adverse events. In contrast, non-steroidal anti-inflammatories (NSAIDs) are more selective in their action due to their targeting of the cyclooxygenases and altering biologically active eicosanoids such as prostaglandins and thromboxanes. However, the NSAIDs require appropriate dosing for safe and effective use due to the fundamental importance of the widely distributed cyclooxgenase targets in physiological processes (e.g., $[52,53])$. In the case of the NSAID drug aspirin, it can be administered daily at a very low-dose for cardiovascular disease modification or 'as needed' dosing at higher concentrations for CNS symptomatic effects (for reviews, see $[54,55])$. It is anticipated that the pharmacodynamic (what the drug does to the body) effects of p38 MAPK inhibitors will be determined by the dosing regimen which must be empirically determined. The concentration-dependent target engagement in microglia treated with a p38 MAPK inhibitor as shown in this report is consistent with the achievement of a desired pharmacodynamic effect through appropriate dosing. However, the potential for dosing microglial product endpoints studied here must be placed in the context of other potential roles, such as effects on phagocytosis/ clearance or neuronal functions, which remain to be dissected.

It is important to note that compound 069A is not a NSAID as it does not target cyclooxgenases. In terms of anti-inflammatory actions, 069A's pharmacological effects more closely resemble those of macromolecular Biological Response Modifier drugs, such as the TNF $\alpha$ blockers Etanercept or Infliximab, that alter inflammation-related pathology and exhibit extended pharmacodynamic effects after each administration. A goal of p38 $\alpha$ MAPK targeted drug development for CNS indications is to generate small molecule drugs that partially mimic the biological actions of macromolecular biological response modifiers, yet are bioavailable, CNS-penetrant compounds that modulate disease-relevant endpoints. The data presented here demonstrate that pharmacological inhibition of p38 $\alpha$ MAPK effectively suppresses the microglial cytokine upregulation response to a number of different activating ligands, raising the possibility for an extended pharmacodynamic effect due to alteration of cytokine production.

In order to explore the potential for an in vivo effect of 069A on cytokine levels, we screened for an effect on the proinflammatory cytokine surge induced by LPS administered ip. The results reveal a clear pharmacodynamic effect on brain cytokine level. Further exploration of the mechanisms for this in vivo effect was not done as part of this study, but deserves a cautionary comment. LPS administered ip will elicit a strong peripheral inflammatory response, which is then transduced to the brain via many pathways (for a recent review see: [56]). Therefore, in the LPS model, one cannot distinguish between a direct effect of a compound on microglia cytokine induction or a more indirect effect that involves reduction of the inflammatory response in the periphery which then leads to a reduction in the CNS response (or a combination of the two mechanisms). Regardless, we previously reported [18] that oral administration of 069A attenuated excessive proinflammatory cytokine production in the brain of an AD-relevant mouse model stimulated centrally with a disease-relevant stressor (oligomeric $A \beta_{1-42}$ ). Therefore, viewing both our current and previous in vivo results in the context of the glial biology results indicates a probable direct effect on microglia as one component of the therapeutic outcome. In addition, our results provide evidence that oral administration of 069A can reduce the levels of IL-1 $\beta$ in the brain brought about by more than one class of in vivo stressor.

\section{Conclusions}

Our results document a role for p38 $\alpha$ MAPK as a critical regulator of IL- $1 \beta$ and TNF $\alpha$ overproduction by microglia in response to TLR ligands, and indicate that $\mathrm{p} 38 \alpha$ MAPK also plays this key role in response to other classes of microglial activators, including $A \beta_{1-42}$. In the context of a rapidly growing literature in CNS drug discovery, the findings presented here suggest that therapeutic strategies targeting p38 $\alpha$ MAPK pathways can be potentially complementary to other disease progression approaches to complex diseases and susceptibility to injury where perturbation of glial-neuronal homeostasis is involved in the mechanism of pathophysiology.

\section{Abbreviations}

(AD): Alzheimer's disease; (A $\beta$ ): $\beta$-amyloid; (CNS): central nervous system;

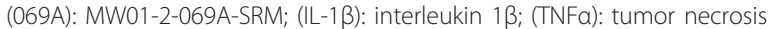
factor-a; (LPS): Lipopolysaccharides; (TLR): Toll like receptor; (MAPK): MitogenActivated Protein Kinase; (MSK1): Mitogen- and stress-activated kinase 1; (MK2): Mitogen-activated protein kinase-activated protein kinase 2; (ATF2): Activating transcription factor-2; (JNK): c-Jun NH2-terminal protein kinase; (ERK): extracellular signal-regulated kinase; (p): phosphorylated. 


\section{Acknowledgements}

This research was supported in part by funding from the Alzheimer's Drug Discovery Foundation (DMW), Alzheimer's Association Zenith grant ZEN-09134506 (LVE), and NIH grants R01 AG031311 (DMW), R01 NS056051 (DMW), and R01 NS064247 (LVE). ADB is supported by NIH fellowship F32 AG037280. We are grateful to Dr. Huiping Jiang at Boehringer Ingelheim Pharmaceuticals, Inc. and Dr. Jiahuai Han at The Scripps Research Institute for the kind gifts of the knockout mice.

\section{Author details}

'Sanders-Brown Center on Aging, University of Kentucky, Lexington, KY, USA. ${ }^{2}$ Dept of Celland Molecular Biology, Northwestern University Feinberg School of Medicine, Chicago, IL, USA. ${ }^{3}$ Dept of Molecular Pharmacology and Biological Chemistry, Northwestern University Feinberg School of Medicine, Chicago, IL, USA. ${ }^{4}$ Dept Anatomy and Neurobiology, University of Kentucky, Lexington, KY, USA.

\section{Authors' contributions}

$A D B, D M W, L V E$ designed the research studies. ADB, BX, LA, ERD performed the experiments. ADB, DMW and LVE drafted the manuscript with the assistance of the other authors. All authors read and approved the final manuscript.

\section{Competing interests}

DMW and LVE are principal investigators on project funding from the $\mathrm{NIH}$ and non-profit disease foundations with development of CNS new molecular entities as the long-term goal. Patents and patent applications covering novel compounds, including the one described here, have been filed by Northwestern University's technology transfer office and licensed to industry.

Received: 23 May 2011 Accepted: 6 July 2011 Published: 6 July 2011

\section{References}

1. Nimmerjahn A, Kirchhoff F, Helmchen F: Resting microglial cells are highly dynamic surveillants of brain parenchyma in vivo. Science 2005, 308:1314-1318.

2. Davalos D, Grutzendler J, Yang G, Kim JV, Zuo Y, Jung S, Littman DR, Dustin ML, Gan WB: ATP mediates rapid microglial response to local brain injury in vivo. Nat Neurosci 2005, 8:752-758.

3. Lehnardt S: Innate immunity and neuroinflammation in the CNS: the role of microglia in Toll-like receptor-mediated neuronal injury. Glia 2010, 58:253-263.

4. Yamamoto M, Takeda K: Current views of toll-like receptor signaling pathways. Gastroenterol Res Pract 2010, 2010:240365.

5. Ransohoff RM, Perry VH: Microglial physiology: unique stimuli, specialized responses. Annu Rev Immunol 2009, 27:119-145.

6. Hanisch UK, Kettenmann H: Microglia: active sensor and versatile effector cells in the normal and pathologic brain. Nat Neurosci 2007, 10:1387-1394.

7. Ransohoff RM, Cardona AE: The myeloid cells of the central nervous system parenchyma. Nature 2010, 468:253-262.

8. Hickman SE, Allison EK, El Khoury J: Microglial dysfunction and defective beta-amyloid clearance pathways in aging Alzheimer's disease mice. $J$ Neurosci 2008, 28:8354-8360.

9. Colton CA: Heterogeneity of microglial activation in the innate immune response in the brain. J Neuroimmune Pharmacol 2009, 4:399-418.

10. Yirmiya R, Goshen I: Immune modulation of learning, memory, neural plasticity and neurogenesis. Brain Behav Immun 2011, 25:181-213.

11. Van Eldik $L$, Thompson WL, Ralay Ranaivo H, Behanna HA, Watterson DM: Glia proinflammatory cytokine upregulation as a therapeutic target for neurodegenerative diseases: function-based and target-based discovery approaches. Int Rev Neurobiol 2007, 82:277-296.

12. Glass CK, Saijo K, Winner B, Marchetto MC, Gage FH: Mechanisms underlying inflammation in neurodegeneration. Cell 2010, 140:918-934.

13. Mrak RE, Griffin WS: Glia and their cytokines in progression of neurodegeneration. Neurobiol Aging 2005, 26:349-354.

14. Cuenda A, Rousseau S: p38 MAP-kinases pathway regulation, function and role in human diseases. Biochim Biophys Acta 2007, 1773:1358-1375.

15. Schieven GL: The biology of $p 38$ kinase: a central role in inflammation. Curr Top Med Chem 2005, 5:921-928.
16. Yasuda S, Sugiura H, Tanaka H, Takigami S, Yamagata K: p38 MAP kinase inhibitors as potential therapeutic drugs for neural diseases. Cent Nerv Syst Agents Med Chem 2011, 11:45-59.

17. Chico LK, Van Eldik LJ, Watterson DM: Targeting protein kinases in central nervous system disorders. Nat Rev Drug Discov 2009, 8:892-909.

18. Munoz L, Ranaivo HR, Roy SM, Hu W, Craft JM, MCNamara LK, Chico LW, Van Eldik LJ, Watterson DM: A novel p38 alpha MAPK inhibitor suppresses brain proinflammatory cytokine up-regulation and attenuates synaptic dysfunction and behavioral deficits in an Alzheimer's disease mouse model. J Neuroinflammation 2007, 4:21.

19. Li Y, Liu L, Barger SW, Griffin WS: Interleukin-1 mediates pathological effects of microglia on tau phosphorylation and on synaptophysin synthesis in cortical neurons through a p38-MAPK pathway. J Neurosci 2003, 23:1605-1611.

20. Sheng JG, Jones RA, Zhou XQ, McGinness JM, Van Eldik LJ, Mrak RE, Griffin WS: Interleukin-1 promotion of MAPK-p38 overexpression in experimental animals and in Alzheimer's disease: potential significance for tau protein phosphorylation. Neurochem Int 2001, 39:341-348.

21. Stine WB, Jungbauer L, Yu C, LaDu MJ: Preparing synthetic Abeta in different aggregation states. Methods Mol Biol 2011, 670:13-32.

22. White JA, Manelli AM, Holmberg KH, Van Eldik LJ, Ladu MJ: Differential effects of oligomeric and fibrillar amyloid-beta 1-42 on astrocytemediated inflammation. Neurobiol Dis 2005, 18:459-465.

23. Kim SH, Smith CJ, Van Eldik LJ: Importance of MAPK pathways for microglial pro-inflammatory cytokine IL-1 beta production. Neurobiol Aging 2004, 25:431-439.

24. Petrova TV, Akama KT, Van Eldik LJ: Cyclopentenone prostaglandins suppress activation of microglia: down-regulation of inducible nitricoxide synthase by 15-deoxy-Delta12,14-prostaglandin J2. Proc Natl Acad Sci USA 1999, 96:4668-4673.

25. Blasi E, Barluzzi R, Bocchini V, Mazzolla R, Bistoni F: Immortalization of murine microglial cells by a v-raf/v-myc carrying retrovirus. J Neuroimmunol 1990, 27:229-237.

26. Kang YJ, Chen J, Otsuka M, Mols J, Ren S, Wang Y, Han J: Macrophage deletion of p38alpha partially impairs lipopolysaccharide-induced cellular activation. J Immunol 2008, 180:5075-5082.

27. Xie Z, Smith CJ, Van Eldik L: Activated glia induce neuron death via MAP kinase signaling pathways involving JNK and p38. Glia 2004, 45:170-179.

28. Gaestel M: MAPKAP kinases - MKs - two's company, three's a crowd. Nat Rev Mol Cell Biol 2006, 7:120-130.

29. Arthur JS: MSK activation and physiological roles. Front Biosci 2008 , 13:5866-5879.

30. Gupta S, Campbell D, Derijard B, Davis RJ: Transcription factor ATF2 regulation by the JNK signal transduction pathway. Science 1995, 267:389-393.

31. Jiang Y, Chen C, Li Z, Guo W, Gegner JA, Lin S, Han J: Characterization of the structure and function of a new mitogen-activated protein kinase (p38beta). J Biol Chem 1996, 271:17920-17926.

32. Stein $B$, Yang $M X$, Young $D B$, Janknecht $R$, Hunter $T$, Murray BW, Barbosa MS: p38-2, a novel mitogen-activated protein kinase with distinct properties. J Biol Chem 1997, 272:19509-19517.

33. Frank S, Copanaki E, Burbach GJ, Muller UC, Deller T: Differential regulation of toll-like receptor mRNAs in amyloid plaque-associated brain tissue of aged APP23 transgenic mice. Neurosci Lett 2009, 453:41-44.

34. Jack CS, Arbour N, Manusow J, Montgrain V, Blain M, McCrea E, Shapiro A, Antel JP: TLR signaling tailors innate immune responses in human microglia and astrocytes. J Immunol 2005, 175:4320-4330.

35. Dilger RN, Johnson RW: Aging, microglial cell priming, and the discordant central inflammatory response to signals from the peripheral immune system. J Leukoc Biol 2008, 84:932-939.

36. Kim C, Sano Y, Todorova K, Carlson BA, Arpa L, Celada A, Lawrence T, Otsu K, Brissette JL, Arthur JS, Park JM: The kinase p38 alpha serves cell type-specific inflammatory functions in skin injury and coordinates proand anti-inflammatory gene expression. Nat Immunol 2008, 9:1019-1027.

37. Neininger A, Kontoyiannis D, Kotlyarov A, Winzen R, Eckert R, Volk HD, Holtmann H, Kollias G, Gaestel M: MK2 targets AU-rich elements and regulates biosynthesis of tumor necrosis factor and interleukin-6 independently at different post-transcriptional levels. J Biol Chem 2002, 277:3065-3068. 
38. Reed-Geaghan EG, Savage JC, Hise AG, Landreth GE: CD14 and toll-like receptors 2 and 4 are required for fibrillar $A \beta$-stimulated microglial activation. J Neurosci 2009, 29:11982-11992.

39. Trudler D, Farfara D, Frenkel D: Toll-like receptors expression and signaling in glia cells in neuro-amyloidogenic diseases: towards future therapeutic application. Mediators Inflamm 2010, 2010.

40. Cameron B, Landreth GE: Inflammation, microglia, and Alzheimer's disease. Neurobiol Dis 2010, 37:503-509.

41. Kawai T, Akira S: The role of pattern-recognition receptors in innate immunity: update on Toll-like receptors. Nat Immunol 2010, 11:373-384.

42. Chaparro-Huerta V, Flores-Soto ME, Gudino-Cabrera G, Rivera-Cervantes MC, Bitzer-Quintero OK, Beas-Zarate C: Role of p38 MAPK and proinflammatory cytokines expression in glutamate-induced neuronal death of neonatal rats. Int J Dev Neurosci 2008, 26:487-495.

43. Mrak RE, Griffin WS: Interleukin-1, neuroinflammation, and Alzheimer's disease. Neurobiol Aging 2001, 22:903-908.

44. Wang XJ, Kong KM, Qi WL, Ye WL, Song PS: Interleukin-1 beta induction of neuron apoptosis depends on p38 mitogen-activated protein kinase activity after spinal cord injury. Acta Pharmacol Sin 2005, 26:934-942.

45. Bhaskar K, Konerth M, Kokiko-Cochran ON, Cardona A, Ransohoff RM, Lamb BT: Regulation of tau pathology by the microglial fractalkine receptor. Neuron 2010, 68:19-31.

46. Origlia N, Righi M, Capsoni S, Cattaneo A, Fang F, Stern DM, Chen JX, Schmidt AM, Arancio O, Yan SD, Domenici L: Receptor for advanced glycation end product-dependent activation of p38 mitogen-activated protein kinase contributes to amyloid-beta-mediated cortical synaptic dysfunction. J Neurosci 2008, 28:3521-3530.

47. Anderton BH, Betts J, Blackstock WP, Brion JP, Chapman S, Connell J, Dayanandan R, Gallo JM, Gibb G, Hanger DP, Hutton M, Kardalinou E, Leroy K, Lovestone S, Mack T, Reynolds CH, Van Slegtenhorst M: Sites of phosphorylation in tau and factors affecting their regulation. Biochem Soc Symp 2001, 73-80.

48. Ferrer I, Gomez-Isla T, Puig B, Freixes M, Ribe E, Dalfo E, Avila J: Current advances on different kinases involved in tau phosphorylation, and implications in Alzheimer's disease and tauopathies. Curr Alzheimer Res 2005, 2:3-18.

49. Colton CA, Wilcock DM: Assessing Activation States in Microglia. CNS Neurol Disord Drug Targets 2009.

50. Morgan D, Gordon MN, Tan J, Wilcock D, Rojiani AM: Dynamic complexity of the microglial activation response in transgenic models of amyloid deposition: implications for Alzheimer therapeutics. J Neuropathol Exp Neurol 2005, 64:743-753.

51. Streit WJ: Microglia and Alzheimer's disease pathogenesis. J Neurosci Res 2004, 77:1-8.

52. Rainsford KD: Anti-inflammatory drugs in the 21st century. Subcell Biochem 2007, 42:3-27.

53. Rao P, Knaus EE: Evolution of nonsteroidal anti-inflammatory drugs (NSAIDs): cyclooxygenase (COX) inhibition and beyond. J Pharm Pharm Sci 2008, 11:81s-110s.

54. Campbell CL, Smyth S, Montalescot G, Steinhubl SR: Aspirin dose for the prevention of cardiovascular disease: a systematic review. Jama 2007, 297:2018-2024.

55. Patrono C, Rocca B: Aspirin: promise and resistance in the new millennium. Arterioscler Thromb Vasc Biol 2008, 28:525-32.

56. Rivest S: Interactions between the immune and neuroendocrine systems. Prog Brain Res 2010, 181:43-53.

doi:10.1186/1742-2094-8-79

Cite this article as: Bachstetter et al:: Microglial p38 $\alpha$ MAPK is a key regulator of proinflammatory cytokine up-regulation induced by tolllike receptor (TLR) ligands or beta-amyloid (AB). Journal of Neuroinflammation 2011 8:79.

\section{Submit your next manuscript to BioMed Central and take full advantage of:}

- Convenient online submission

- Thorough peer review

- No space constraints or color figure charges

- Immediate publication on acceptance

- Inclusion in PubMed, CAS, Scopus and Google Scholar

- Research which is freely available for redistribution

Submit your manuscript at www.biomedcentral.com/submit
Biomed Central 